\title{
3 The Bucket List and More
}

Exploring Care Practices in

an Australian Residential

Aged Care Home Through a

"Narra-theatrical" Lens

\section{Janet Gibson}

Marcia Bannister and Jessie Anderson lived in the Australian residential care home, Starrett Lodge, operated by Uniting Care ${ }^{1}$ and located on the central coast of New South Wales, Australia, until their deaths in 2019. Though both Marcia and Jessie lived with dementia, Marcia held the "role" of Bucket List Sales Manager and Jessie that of Bucket List Assistant Sales Manager. In addition, Marcia and Jessie were the List's co-instigators, and actively involved in setting up the Calendar Girls Project (2017), which was a fundraiser for the List. The Bucket List involves residents drawing names out of a hat at intervals over time (usually every month) to determine which of them, on that occasion, gets to have a wish fulfilled before they die: dreams accomplished have ranged from a trip to an expensive restaurant in a chauffeur-driven car to skydiving jumps. As many residents cannot afford to participate in the Bucket List without financial help, most likely because of their lower socio-economic status, ${ }^{2}$ List activities are subsidised in various ways. One past example was the composition and publication of residents' life stories, followed by the sale of these books to family and friends (Sanchez Interview no. 4); other examples include the residents baking and selling biscuits and the sale of calendars featuring the residents photographed in various locations and poses.

Deeming the Bucket List (BL) and the Calendar Projects (CPs) to be "care practices" for older people, including those living with dementia, I offer them as my principal objects of study in this chapter to explore what is generated when these practices are viewed through the intersecting lenses of "theatrical narrativisation" and "performance consciousness." "Theatrical narrativisation" is a term I have coined to describe individual and communal story worlds acknowledged by the "spectators" viewing and interacting with the "performers" of these worlds. "Narra-theatrical," another neologism of mine, is an analogous descriptor to "theatrical narrativisation." "Performance consciousness" is defined by Richard Schechner as that which "activates alternatives: 'this' 


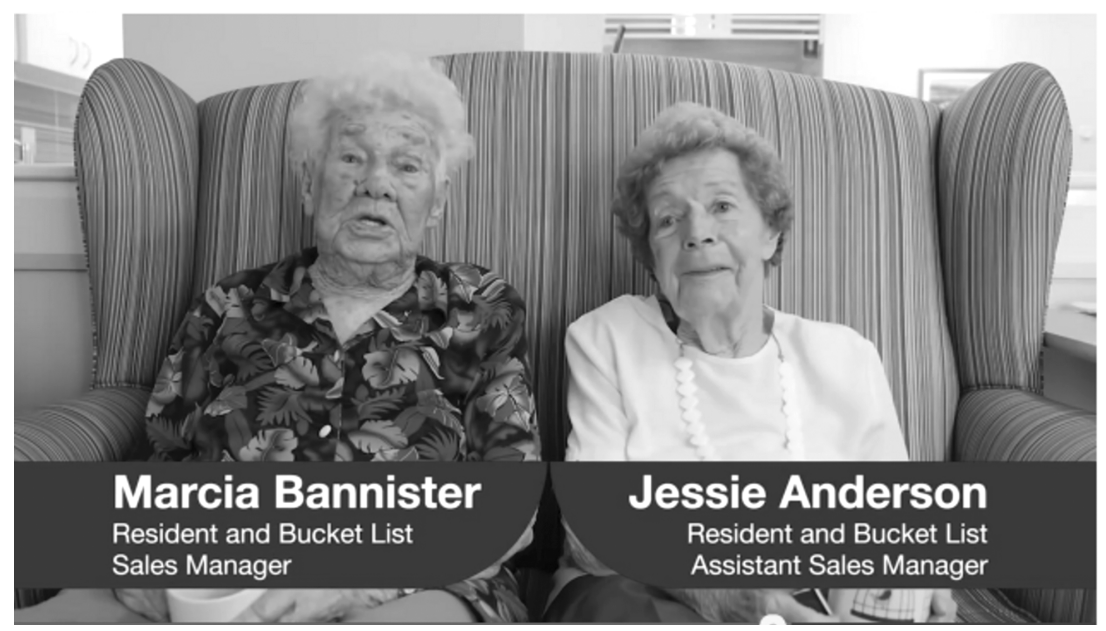

Figure 3.1 Video still from Finding the Why: Enabling Active Participation in Life in an Aged Care Facility. Used with permission of Corinne Maunder.

and 'that' are both operative simultaneously. . . [it] is subjunctive, full of alternatives and potentiality" (Between 6). Here, Schechner is not alluding to any one person's consciousness but isolating what happens when "performers - and sometimes spectators too - are changed by the activity of performing" (ibid. 4; my italics). Schechner argues that in performance, ordinary people and objects can be transformed as they are simultaneously "'not themselves' and 'not not themselves," allowing "multiple selves [to] coexist in an unresolved dialectical tension" which may either be permanent, such as in initiation rituals, or temporary, as in art theatre (ibid. 6). In this chapter, I intend to deploy all these concepts to bring into sharp focus the interrelationship of care, subjectivity, narrative and performance. ${ }^{3}$

Performance is sometimes defined narrowly, solely in terms of its aesthetic manifestations. While acknowledging that theatre, dance, music and performance art are clearly performances, Schechner contends that performance must be understood more broadly as a continuum of actions extending from "ritual, play, games, sports, popular entertainments, the performing arts . . . and everyday life performances to the enactment of social, professional, gender, race, and class roles, and on to healing (from shamanism to surgery), the media, and the internet" (Performance 7). For Schechner, another way of understanding the performance continuum is to see that theatre, dance, music, film and other artistic displays are the "is" of performance, deemed so from historical-social contexts, 
convention, usage and tradition (ibid. 12). However, Schechner contends that anything can be studied "as" performance, meaning that performance questions can be asked of whatever is being studied, including questions about location, appearance and behaviour, staging, clothes worn, any objects in use, as well as the roles people play and how these change over time (ibid.12, 22).

In this chapter, mobilising Schechner's idea that performances of everyday life, including performances of care, might be studied "as" performance, I present an analysis of the BL and the CPs on the basis of questions derived from the methodological repertoire presented earlier, bolstered by theatre theorist and semiotician Patrice Pavis' "performance analysis." I have undertaken this inquiry, not by visiting the care home and viewing the practices myself as "live" performances but through recourse to what Pavis terms "supplementary documents" (40). In the case of the BL and the CPs, these documents comprise a short film about the BL (Corrine Maunder's Finding the Why), ${ }^{4}$ a TV show about both the BL and the CPs (SBS television's Dancing with Dementia) ${ }^{5}$ and other media sources such as newspaper articles. I first "met" Marcia and Jessie in Finding the Why. Unfortunately, I never met them in person. My research is also based on four structured interviews with the activities officer at Starrett Lodge, Vicki Sanchez, all conducted via email and telephone. Sanchez worked at Starrett Lodge for 13 years. She started working there as a care attendant, gaining skills as she worked. A year into this work, she stepped into the role of activities officer, going to TAFE (Technical and Further Education) to complete a Certificate Four in Lifestyle. Sanchez was a key figure in helping the residents set up the $\mathrm{BL}$ and the CPs.

In sum, in this chapter, I harness performance tools to reframe two particular care practices (the BL and the CPs) as "narra-theatrical." In so doing, it is my hope that this reframing will encourage other ways of "seeing" in residential care homes for older people - arguably more ethical ways - in which the capacities and creativities of those who live in care homes may be perceived and celebrated, with implications for improving quality of life. My stance here is avowedly utopian (Dolan), with hope that the lenses of theatre and performance can afford promising ways of positioning older people, including those with dementia or memory loss, even in unofficial "theatre" spaces. Proposing these practices as "narra-theatrical" is a hypothetical move on my part; that is, at present, these practices are not interpreted as "narra-theatrical" by the participants and the institution. Before outlining my rationale for deploying the phrase "narra-theatrical" and pursuing the previous arguments through examining the $\mathrm{BL}$ and the CPs, I will explore the relationship I hope to elucidate between performance, spectatorship and care, which supports and drives many of my arguments in this chapter. 


\section{Janet Gibson}

\section{Performance, Spectatorship and Care}

Performance requires spectators. If we accept the idea that "we are all, in a manner of speaking, performers" (States 108), then it follows that we are all also spectators to the performances of others in our lives. In my view, this dyadic partnership has an ethical dimension which is actuated through intersubjective embodied communicative encounters. These encounters may also be deemed creative when the performers in them (residents at Starrett Lodge in this case) are encouraged, or allowed, to adopt "roles" that move beyond the sometimes restrictive "roles" allocated to them by the spectators in their lives (family, carers and other residents) because of their age or illness. If these encounters continue over time and are based on mutual respect, then I argue that an ethics of care is likely set in motion. ${ }^{6}$

Anthropologist Steven P. Black makes a similar point about the "fundamental bidirectionality" of care as a basis for ethics when he writes:

Social activities of care both constitute and are made relevant by morally/ethically framed relationships with others and oneself. Although it is not always recognized as such, embodied communication is central in care activities and in the constitution of moral/ ethical care. Care is instantiated in interpersonal encounters through the social organization of diverse semiotic resources such as gesture, facial expression, body orientation, prosody, phonology, morphosyntax, the materiality of media artifacts, and the built environment.

Theatre and performance rely on embodied semiotic resources, as does care. The latter is a complex term to define: "a shifting and unstable concept" which is variously applied to different individual feeling states, the practices of medicine, health and family caregiving, as well as biopolitics and discourses (Buch qtd. in Black 80). But as Black contends, most "understandings of care have in common an emphasis on relationality and activity" (ibid.; my italics). Sufficient to note here is the premise on which this chapter proceeds: that a "care practice" is an embodied, responsive activity/engagement between at least two people in a care facility, an activity that is respectful of each person's selfhood even if that person is at a more dependent and vulnerable stage of life compared to others in the encounter (e.g., the residents compared to the care workers). At its nucleus, a "care practice" is one that understands that to be human is forged in relationship with others.

The practices at the heart of this chapter "perform a mode of care" evident in their "caring structures," that is, evident in the care taken in their development and enactment (Stuart Fisher 2-3). This type of care defies those insistent " 'care-less" " processes increasingly evident in the 
running of care homes as profit machines in global neoliberal economies (ibid.). With these homes, the focus is on economies of profit and loss measured through regimes of formulaic efficiency, whereas the practices examined in this chapter can be viewed as embodied and artful, invoking the affective qualities of "attentiveness, sensitivity and responding to needs" (Held 39) and gesturing to an "aesthetics of care," defined as "a set of values realised in a relational process that emphasise engagements between individuals or groups over time" (Thompson 430, 437). ${ }^{7}$

Although there are several other lenses through which the BL and the CPs could be construed, an obvious one being social citizenship, ${ }^{8}$ as a theatre and performance studies scholar, it is the ethical and creative power of the "gaze" of theatre and performance on care and its practices in care facilities for older people that I want to actuate in this chapter. Underutilised in relation to dementia, care and age studies scholarship in general, the theatrical "gaze" and its companion "performance consciousness" provide unique challenges to the "diagnostic gaze" (Kuppers 137) predominant in many care homes and in views of the older people living in them.

I will elaborate. The "diagnostic gaze" is activated when older people living with dementia (PLWD) are seen primarily as embodiments of an impaired brain and their behaviours as symptoms of awful diseases for which there are no cures. It is also activated when older people in general are seen only in terms of what they have lost because of likely changes in some of the physical (and cognitive) capacities they might have had when younger. This is the "master narrative of decline," in Margaret Morganroth Gullette's words (130), a narrative as much responsible for the effects of ageing on older people as biology itself, constraining their identity formations in a net of debility. As Gullette argues, socio-culturally located ideas about ageing often constrict the choices older people and those with dementia can make in their lives. But, as noted earlier, "performance consciousness" creates spaces of possibility and transformation; it activates alternatives. As an active agent of performance consciousness, theatre too might open spaces of possibility. Even though theatre as an art form might conform to, rather than challenge, decline narratives, its toolkit contains role-playing, a vital counter to decline narratives, which when put into use might allow people of any age to be who they were at previous times of their lives or to become someone they may never have been. In this chapter, the theatrical "gaze" and "performance consciousness" are presented as alternatives to deficit views that do not take into account the still extant creative possibilities of older people living in care homes, including those living with dementia, and what they might have to give to their peers and carers in intersubjective encounters.

As a parenthesis, I acknowledge that some people in care facilities, such as those with late-stage dementias, might not be capable of doing very much at all: they could be in a coma, for instance, or unable to 


\section{Janet Gibson}

communicate using words. However, I maintain that the possibility exists for seeing them as able to engage with their care partners, ${ }^{10}$ if only affectively, not cognitively, in small moments, for example, through bodily responses, such as crying or smiling at care partner prompts. My idea is aligned with Eva Feder Kittay's notion of the "completion of care" where, because the body can take up care, it deserves to be treated with dignity (see van de Kamp). However, these views require a shift on the part of the care partner in the intersubjective encounter and this change is connected to how subjectivity is conceived and the ethical implications of this shift. There is not scope in this chapter to address these ideas in detail, but they are embedded in the notion of ethical spectatorship and how we might "see" people differently through the lens of theatrical narrativisation.

\section{Why "Narra-Theatrical” Practices?}

I frame the practices explored in this chapter as "narra-theatrical" for two main reasons. One is to expand the meaning of narrative in dementia and care practices and studies; the other is to acknowledge the performative or playacting element of these practices. ${ }^{11}$ Turning first to narrative, I must underscore at the outset its polyvalence. For my purposes here, I take it to be a sense-making device (Herman 2013, Hutto 2007a, 2007b qtd. in Bitenc 5) braided to the personal, human-scale, everyday experiences of people and their life worlds. I also see it as strongly knitted to the grander, though limited, cultural repertoire of stories on which we all draw to tell our personal stories (Frank). In the case of dementia, I label this restricted arsenal of narratives the "right kind" of dementia story (Gibson 2), circulating accounts of loss, despair, failure, tragedy and burden and not telling of the extant or nascent abilities of people living with dementia. It focuses on their pasts, or on futures made grim for us all by the probability of a "silver tsunami" coming to destroy lives and push societies towards catastrophe.

The "silver tsunami" is a metaphor that has been used frequently across media platforms, particularly those reporting on the economy such as The Economist and Forbes magazines (see, for example, Das) to augur a massive growth in ageing populations, which these media outlets predict will pose a huge burden on younger people. Most gerontologists would agree that there is indeed a contemporary global trend of ageing without any parallel in the history of humanity (Mangan 19). In 2045, the number of old people is expected to exceed the number of the young with accompanying economic and health care impacts on many societies (United Nations qtd. in Mangan 19-20). But it is worthwhile considering that the associations accompanying this trend - words such as "crisis," "catastrophe" and "tsunami" - could do as much damage in the ethical sphere as the predicted trend could do in the economic. When old people 
populate media narratives as the main drivers of these changes, draining personal or familial emotional, physical and financial resources, then it follows that these dependent humans will likely be framed as "burdens" to the economy, to society, to us all. This is partly because, as literary theorist Lucy Burke argues, the language of economics has infiltrated common thinking about relationships and love; in particular, "the logic of the market and its values now infiltrates the experience and perception of what it means to live with dementia" (26) and, I would add, what it means to live in a world with older people. As Burke argues, reducing love and relationships to "a form of exchange" leaves no room for understanding or embracing relationships with those who fall out of "the logic of this 'contract'" (28): those who are perceived as unable to give back something in return for a care investment.

Apart from these "burden" narratives, reminiscence features as one of the most popular psycho-social interventions in care homes today, via "life-history discussions, life writing, life reviews, narrative and reminiscence of various kinds" (Mangan 124-5). For those living with dementia, it often plays out as a narrow band of life-story practices (e.g., My Memories scrap books and Life Story work) restricted to particular structures and styles, while other types are ignored. For older people as a rule, reminiscence has become accepted as a primary means for the older person to look back on his/her life and reflect on past experiences, including unresolved difficulties and conflicts, and in this way to find some peace. Gerontologist Robert Butler proposed reminiscence to be a "naturally occurring, universal mental process" (66). Although there are some good reasons for the use of reminiscence one being that many people living with dementia remember more from their pasts (long-term memories) than their recent present (working memories) - I argue that expanding the narrative palette would help to reimagine the personhood of older people with or without dementia, at a broader socio-cultural level. Only conceiving of older people in terms of who they were rather than who they are now or who they could $b e$, may be constricting, not only of their possibilities, but those of the narrative form itself. I contend that performed narratives that deviate from a reliance on the word need to be promoted, including new stories or ways of performing them that more fully understand and build on the capacities and creativities of older people and those living with dementia.

In turn, I think that these reconfigurations of narrative could challenge the current negative myths, the "right kind" of dementia stories and decline narratives that circulate about older people. Through first reinterpreting certain practices played out in residential care homes as "narra-theatrical" and then valuing them as such, older people could be seen as productive (or even positively disruptive) members of their immediate residential communities. 


\section{Janet Gibson}

In referring to older people as "productive," I am not sanctioning an ableist neoliberal valorisation of productivity. Instead, I am drawing on disability theorists David Mitchell and Sharon Snyder's idea of "the capacities of incapacity" (180). Mitchell and Snyder, writing in reference to people living with "communication - and cognition - based disabilities," argue that these people have been subject to "imprisoning cultural concepts of inferiority" $(28,183)$. Along with Mitchell and Snyder, I argue for people living with dementia and older people to be seen as "potentially active [and] agential" (183) and, in Elizabeth Grosz's terms, for their lives to have "the condition of, or capacity for action in life" (Grosz qtd. in Mitchell and Snyder 183). Seeing older people as productive on their own terms means acknowledging their capacity for action, their potentiality. Productivity as used here in reference to the residents of Starrett Lodge is opposite to what Mitchell and Snyder term the "flattening gestures" (29) that limited neoliberal ideas place on older people's ingenuity: ideas which facilitate the restrictive "roles" often allocated to them by care home staff who are notoriously "risk averse," as Colin McDonell, one-time manager of Starrett Lodge, tags them in the film Finding the Why (12:10). McDonell is a registered nurse who worked for Uniting Care as a manager for 15 years and is now a Dementia Consultant at Calvary Care and an Honorary Fellow at the Faculty of Science Medicine and Health at the University of Wollongong, Australia. He contends that care staff commonly encourage residents to stay away from any activities perceived as unsafe and that residents in many of these care facilities also usually wait for care home staff to do things for them because that is the way many institutions work. In the case of the BL and the CPs, the residents have disrupted common care home procedures by instigating activities that they want to do without always gaining the permission of the authorities in the home and often by insisting on their right to a dignity of risk in some situations (see the SBS Insight TV show Dancing with Dementia 28:04-42).

The second, and predominant reason I collocate the words "narrative" and "theatrical" in reference to the specific practices examined in this chapter is to acknowledge their performative or playacting elements. A standard dictionary definition of "theatrical" usually defines it first, as "of or relating to theatre," commonly seen as either a place or a form of high art, and second, as " 'exaggerated or affected'," especially as related to human behaviour (Quick and Rushton 1). While acknowledging this negative construal of the word "theatrical," I want to examine what is often overlooked when thinking about what theatre is, to make clear in what way and for what reasons I favour the term "theatrical" in this chapter.

Theatre derives from the Greek "theatron," denoting "a place for looking," which carries with it dual meanings of location and at the same time "a particular form of sense perception" (Balme 1), the latter 
meaning tending to be overshadowed by that of its located-ness. This latter connotation emphasises the imaginative collusion of the spectator and the performers, and takes the meaning of theatre away from its association with buildings and high art. The associated term theatricality underscores that things, actions, people and places are not in themselves theatrical but are rendered as such by a combination of aesthetic conventions and discursive practices that determine around which phenomena we place the frame of theatrical apprehension (Balme 89-91). In tandem with this point, I want to stress that it is of critical importance to remember that in viewing the bodies, actions and behaviours of other people, that is, in spectating, what we see is not "real" in any objective sense. We are always looking at bodies that are discursively constructed and regulated through language, socio-cultural practices and institutions: that is, our perceptual experience is governed by these systems, to a large extent, a vital point to remember in reference to the "reality" of ageing and dementia.

A final important point I want to make here is in regard to the political potential of theatre, which is embedded in its capacity for pretence, that is, in showing things that do not exist (Kelleher 10) and in proposing alternative realities, while still being in contact with the "grain of the absent reality" (ibid. 24). In other words, through the theatrical lens, things can be brought into existence that might not otherwise have been thought of, allowing spectators to deliberate on what could be different to the present situation (ibid. 26). My argument is that if we see the participants in the $\mathrm{BL}$ and the CPs through the lens of theatre and performance, with the care home and other environments acting as the "stage" for their performances, then the possibility exists to begin to move away from ingrained and limiting discourses about older people and those living with dementia in care homes towards imagining other, more magnanimous ways of seeing them.

\section{Bucket List Origins}

Before 2010, when the BL started, residents at Starrett Lodge did all the usual activities likely to be found in a care facility for older people, such as bingo, craft and games. The genesis of the BL can be tracked to residents watching the film The Bucket List starring Jack Nicolson and Morgan Freeman. After viewing the film, some of the Starrett Lodge residents told Vicki Sanchez, the activities officer, that they were "looking for an adventure" (Interview no. 1). When Sanchez suggested that the residents write their own "bucket lists," they all laughed at the title with good humour (ibid.). The colloquialism contained a tongue-in-cheek nod to the death they were keenly aware was coming as well as a commitment to achieving a few of their dreams and doing "something outrageous" before they died (ibid.). (The performative potential of this latter phrase 


\section{Janet Gibson}

is clear, presaging the ways in which the BL activities undertaken were often highly dramatic, such as skydiving.) Thus, the birth of the practice was firmly embedded in an intertextual relationship with both a film and a colloquialism, to which the film also owes its title. That is, right from its inception the practice references narrative and performance, connecting the practice to a performed story world in the film where two older, terminally ill men travel the world together to do things on their wish lists before they die; also, right from the beginning, the practice connects the real (the wishes of the residents) and the imaginary (the film).

When the BL started, there were 60 residents and the corresponding number of rooms at Starrett Lodge (Sanchez Interview no. 3). Although only 15 rooms were allocated specifically for people living with dementia, most of the residents had some memory loss (ibid.). Together, the residents and Sanchez decided that the order of action would be determined by drawing residents' names out of a hat. The issue though was finding money for the activities. Sanchez told me that "no one [in Uniting Care or indeed the residents themselves] was going to pay for it" (Interview no. 1). So, to support the BL, the residents, spurred on by Marcia and Jessie, decided that they would bake biscuits and sell them to the other residents and staff. According to Sanchez, Marcia would go door to door with the bags of biscuits, beautifully tied into bundles of six, with ribbons attached by Jessie. Marcia would do this "rain, hail or shine" (Interview no. 1), going from one room to another in the facility. Sanchez and the residents aimed to do a BL activity monthly, and Sanchez notes that during her time working at Starrett Lodge, she helped arrange BL events for approximately 45 people, with some residents doing a BL activity more than once (Interview no. 3). A typical BL item costs about 300 dollars, which takes roughly three months to raise. Some examples of List activities include drinks and lunch at a restaurant, helicopter rides, massages and day trips to various scenic locations. The BL won a 2014 better practice award from the Australian Aged Care Quality Agency.

\section{A “Narra-Theatrical” Lens}

Several points of interest arise when the "care practices" at the heart of this chapter are viewed through a "narra-theatrical" prism, rather than as responsibilities for tasks that might not normally be expected of older people in a care home. Firstly, there is the undoubted theatricality of many of the fundraising pursuits underpinning the Bucket List (which are all brought to life in Dancing with Dementia). In the case of the baking and selling of biscuits to raise money for the BL, the senses of scene, property and ritual in this fundraiser become palpable, with the narrative in operation evident as one of capacity and agency as opposed to one of decline and loss. In Dancing with Dementia, one important scene which underpins this narrative is the hum of a big "industrial" 
kitchen thronging with residents working together and care attendants helping. Though the residents were not unfamiliar with the kitchen, they had never "claimed" it in this way before the advent of the BL (Sanchez Interview no. 4). The ceremonial elements of this scene comprise the habitual cooking in the kitchen with the staff and the residents working and chatting together, wearing their hairnets and, sometimes, their blue latex gloves. The theatrical properties of the kitchen scene include the cellophane biscuit bags and the ribbons of various colours to tie them up. Other theatrical scenes not recorded in Dancing with Dementia but told to me by Sanchez (Interview no. 4) include the regular jaunts taken by Marcia around the multiple residential buildings at the facility at certain times of the day regardless of the weather, with a basket full of gaily beribboned biscuit bags, knocking on the residents' doors and breaking their isolation. The final story that emerges from these fundraising activities is one of camaraderie, connection and commitment. It tells of intersubjective, embodied and communicative encounters between residents and between residents and staff, arguably activating an ethics of care. Intersubjective, because the residents are forging relationships with each other and the staff; embodied, because they are using their bodies to bake and wrap biscuits; and communicative, because they are talking to each other and the staff as they go about their activities.

Secondly, Marcia and Jessie were the "managers" of the BL. As I noted at the beginning of the chapter, "performance consciousness" (Schechner, Between 6) activates alternatives: "this" and "that" are both operative simultaneously. If we take this lens to look at Marcia and Jessie, then we can see that they were both managers of the List and acting as managers in an obvious conflation of the real and the imaginary. I say this because they directed the project when they were alive, and they were the main initiators of the fundraising activities for the List and in this way were, in a sense, leaders of other residents at the home. However, they were not managers in any commonly understood sense of the term, except, as more and more residents wanted to be on the BL, Marcia and Jessie worked with other residents in the home and delegated some activities to them. For example, Jessie organised the "process line for the production of the biscuits" (Sanchez Interview no. 2). But unlike managers commonly do, they did not receive a wage; they also did not have to write reports to more senior staff and so on. But involving themselves in the project meant that they did get to act out these "roles" to the extent possible when they were 80-year-old (plus) residents of a care home.

The theatrical part of the phrase "narra-theatrical" links the day-today activities Marcia and Jessie were involved in with a hyper-real conception of their "roles." The fiction, that they are managers of the BL, meets with the absent reality, that they are in fact not managers but residents, to underscore what is possible rather than what is not possible. Having others (spectators) engage with their "roles" means that both 
the performers (in this case Marcia and Jessie), and the spectators (in this case the workers in the facility and the other residents) are complicit with the fiction, which allows dual personas to emerge, held in a dialectical tension. As performers in the BL fundraising scenes, Marcia and Jessie were "changed by the activity of performing"; that is, in Schechner's dispensation, they were simultaneously "'not themselves' and 'not not themselves" "(Between 4, 6; my italics). Seeing themselves as BL managers allowed Marcia and Jessie to grow in confidence such that their agency in the home increased; they started to think about other ways in which they could express themselves and whether or not they needed permission to do so, as is evidenced in the CPs, to be discussed shortly.

Jessie and Marcia's first BL activity involved hiring a limousine to go for drinks by the water together, as they had become inseparable friends at the facility. On this occasion, Jessie, in Dancing with Dementia (25:24), exposes what can be interpreted as another "narra-theatrical" element of the BL, when she refers to being treated like "a lady" by the waiter at the establishment where she and Marcia went for drinks. Looking at the activity through the lens of theatrical narrativisation, rather than just as an outing, what is revealed is that Jessie was able to move away from her "role" of resident of a care facility in a lower socio-economic area who, being on a limited income, would not be able to treat herself to such an outing. In her own terms, she had become "a lady." Jessie had actively changed the narrative she was living in, if only temporarily, through dressing up for the occasion, with makeup and a corsage. Jessie stepped into the "role" of someone who could afford to be driven to the restaurant in a limousine, a car often associated with wealth and celebrity. On top of that, the waiter responded to her in "role," treating her like a lady in what can be seen as a "walk-on" part in the theatrical narrative. But when viewed through the lens of ethical spectatorship, he can also be seen as responder to the call from Jessie to be treated like the lady she had dressed up to be.

\section{Other BL Activities and Care}

Skydiving is another popular BL activity. The first resident to skydive was an 85-year-old who did not have dementia. Although he had jumped from a plane when he was younger, his family, at first, would not give permission for him to do so, as they were worried about the risks involved. The facility manager at the time, Colin McDonnell, and other care workers at Starrett Lodge, like Vicki Sanchez, could see how much this skydive meant to the resident and supported him to do it - finally negotiating, after a tussle with the family, the necessary permission for him to do the dive. His response to the flight was "I feel ageless" (Sanchez Interview no. 1). More recently, a skydive was taken by another Starrett Lodge resident, Elmer Anderson, a man with Lewy Body Dementia 


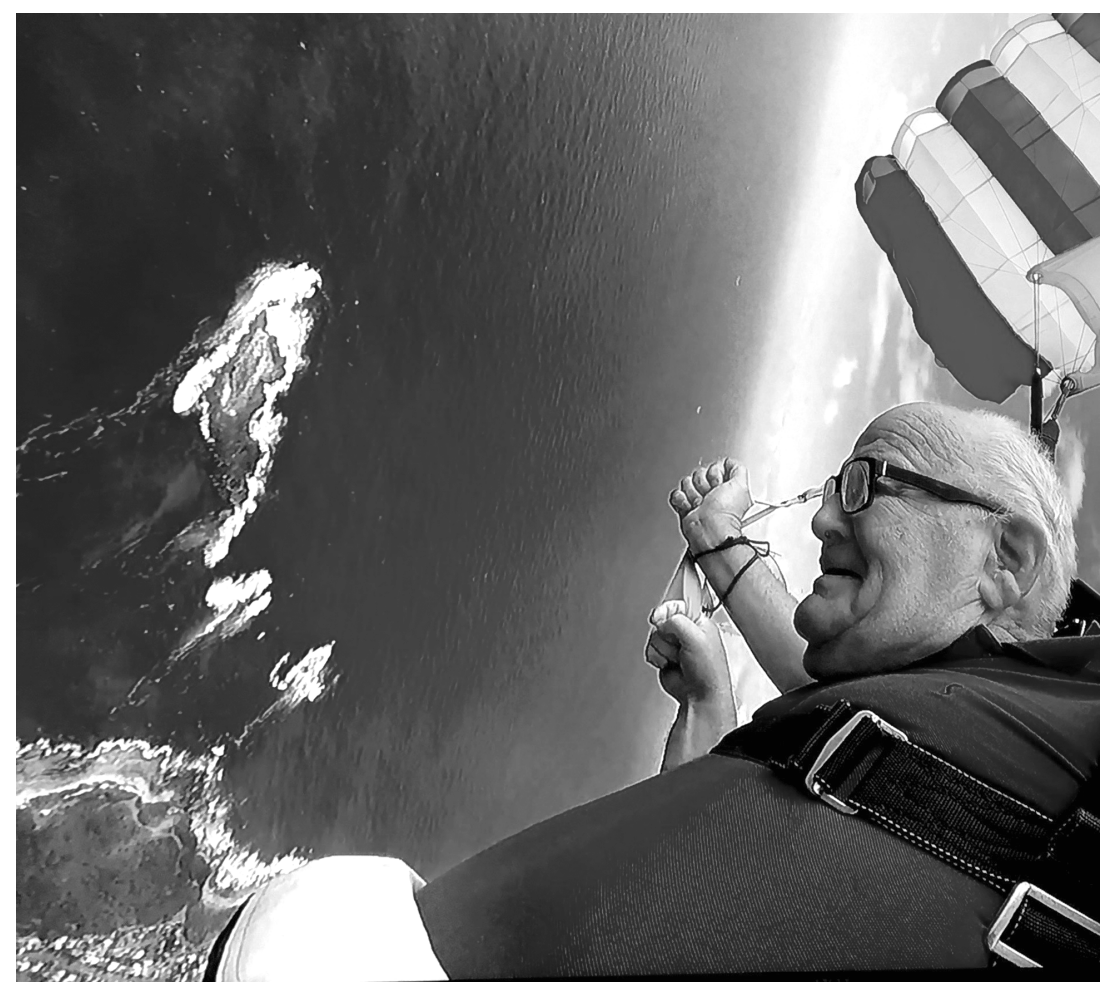

Figure 3.2 Elmer Anderson's Bucket List. Photo by Skydive Photos. Used with permission of Brooke Grundy.

who had never done this before (see Figure 3.2). He was not worried about the risk involved, as he "was going to die anyway" he told Sanchez (Interview no. 1).

The struggle to allow the 85 -year-old to skydive is an example of feminist care ethicist Nel Noddings' "engrossment" in action. For Noddings, care should be undertaken above and beyond professional duty; in this way it becomes relational, particular, not bound by generalities and rules (17). For Noddings, variation is to be expected. Engrossment lives in the variable and never fully understood person who is other than oneself, in the "particular" other, in a specific set of circumstances (17). Kittay's "completion of care" is also activated when care partners take the particularity of each situation and person into account "to see who they are, who that person is, what their life looks like, the way they are speaking" and so on (van de Kamp n.p.; italics in original). In contrast, when the focus in a care home shifts from seeing older people, including those living with dementia, not as particular people but as "problems," 
then rules - rather than a characteristic variation in response to the needs of the cared-for - will predominate.

But Kittay's ideas need to be tempered by acknowledging the impossibility of ever seeing things or people as they really are (Crary qtd. in Bleeker 27). Things, and people, are always presented from within a certain "vision," prisms dominated by culturally restrictive discourses that become naturalised over time. In the case of older people living in care facilities, once they are living in care homes, or even before, these dominant discourses tend to be about loss, deficiency, decline and incapacity; the "diagnostic gaze" (Kuppers 137) is also likely still in operation. It is in this regard that the "narra-theatrical" gaze and "performance consciousness" could be useful activators of other ways of seeing which open up possibilities for those living in care homes. I will now turn to the companion project for the $\mathrm{BL}$, the CPs, to galvanise the "gaze" of theatre and performance in this fundraising venture.

\section{The Calendar Projects}

Two calendars have so far been produced to support the BL activities one in 2017 and the other in 2019. In this endeavour, the residents were following the example of numerous other Australian calendars produced by organisations to make money, where usually young men or women, who are often celebrities to some degree, are photographed nude or partially clad. ${ }^{12}$ The first project was instigated by the women at Starrett Lodge, steered by Marcia and Jessie, who did not seek permission from management before they went ahead with this project. (Not seeking permission before acting is, in this instance particularly, a creative and agentic initiative, which arguably can be linked to the effects of the roleplaying undertaken by Marcia and Jessie, in particular, in the BL.)

In Calendar Girls 2017, the female residents of Starrett Lodge were photographed to look as if they were nude (in fact, it was only their shoulders which were bared). ${ }^{13}$ The more recent 2019 calendar features the men in the Lodge with their shirts off, performing "roles" for the calendar. Figure 3.3 shows a man posing as a firefighter. Other men posed with vehicles (including a motorcycle and a Cadillac). A male resident impersonating a biker was photographed on a motor bike, wearing leather pants and a leather jacket. He told Sanchez that posing for the photo was "one of the best times of his life" (Interview no. 1). One resident posed in a boxing ring, another as a baker in an apron, and Elmer Anderson posed as Mr July in a garden, with the rubric "Manscaping" above his image. In some of these instances, the men were expressing a continuity of identity in that these were interests from their lives as younger men; in other instances, they were using their imaginations to create new "roles" for themselves. With both, they were evidently acting out stories of importance for them, which either helped them to repair 


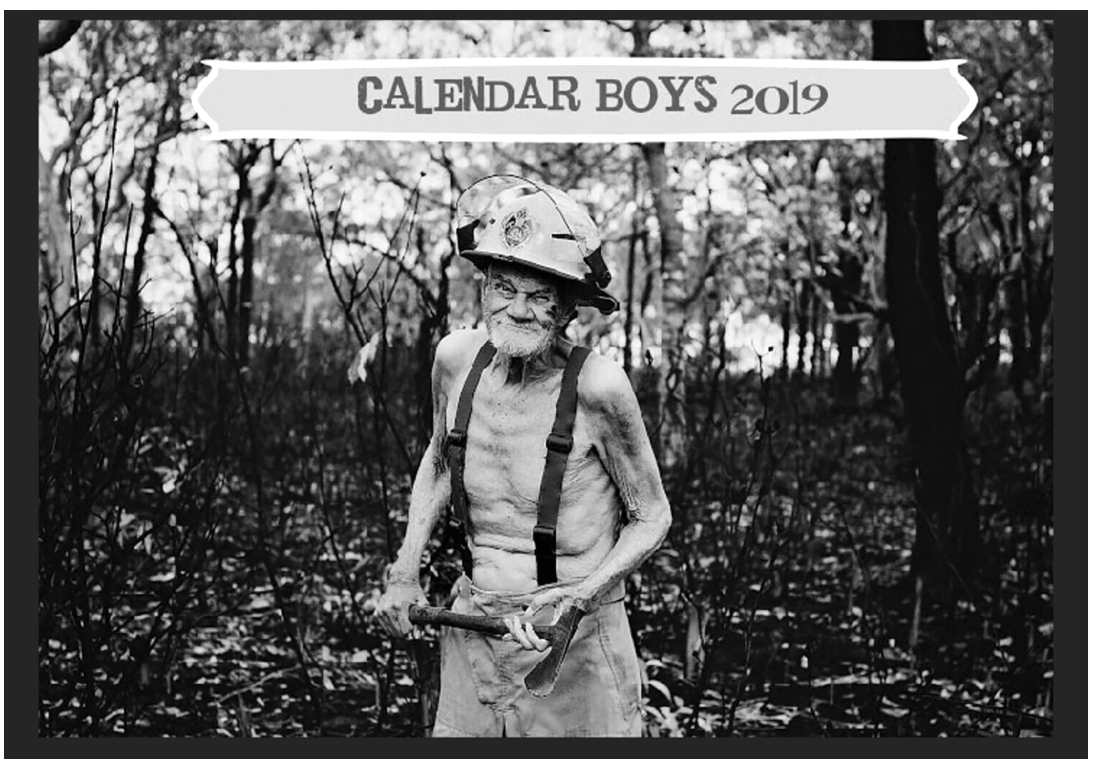

Figure 3.3 Calendar Boy. Photo by Trudi Sanchez. Used with permission of Trudi Sanchez.

identities fractured by moving into the home or to connect with personas they had never had.

It is my contention that the performance-based narrativisations of the CPs gave a form to those identities damaged by the move to a care home and advancing age and dementia; they also provided a way for the men in particular to contribute to raising money for the BL, given that the men did not usually participate in the baking activities. In playing the role of a biker or a firefighter and so on, the men were able to put on costumes and use props to re-experience what it felt like - in the case of the biker, for example - to be young, fit, physically powerful and (possibly) sexually alluring again. (The biker's costume consisted of black leather pants and his prop was a big black motorbike.) In other instances, the residents experienced the feeling of being in costume and propped up for the first time, doing something they always wanted to do but didn't when they were younger, perhaps because in the past they were more concerned about people's opinions. Residents "will have a go at anything," Sanchez told me, as they have lost the stultifying concerns about "what people might think" which they might have had when they were 20 to 40 years younger (Interview no. 1). Through their "narra-theatrical" performances in the CPs, the residents were able to act in roles that, even if for a limited time, reinstated the sense of agency usually not accorded to older people living in residential care homes. 
Seeing the CPs through the lens of theatrical narrativisation unlocks a way of perceiving older people living in care homes as more than just embodiments of problematic deficit discourses. Role plays and role shifts activate "performance consciousness" (Schechner, Between 6) and facilitate the revisioning of the subjectivity of these older people, allowing new types of relationships to be forged with others, principally their care partners and communities. This can be seen in Dancing with Dementia, when the manager Colin McDonell expresses a mix of surprise and pride that the residents did not first check with him about undertaking the CPs. The creation of new types of relationships with their communities is also evidenced in the fact that the residents' activities have been written up in several local newspapers, and they have appeared on various national television shows as celebrities of the moment. After the first Calendar Project, the residents were invited onto Sunrise Channel 7: appearing on TV then became a Bucket List activity. They have become visible, and their voices are being heard on local and national television stations and in other media.

\section{The Bucket List Today}

Presently (as of January 2021) there are rooms for 80 residents at Starrett Lodge, in contrast to the 60 rooms when the BL started in 2010. The BL today involves many more residents who all cook, bake and do whatever they can to raise money to achieve their own and others' BL goals. According to Sanchez (Interview no. 2), there are no residents who do not want to be involved in the BL or its fundraising activities because they all want to have their wishes fulfilled. Of note is that the baking activities that support the success of the List were a large part of many of the residents' lives before moving into the Lodge, especially for the female residents. These everyday practices of identity (Lloyd 205) are frequently taken over by institutional care workers when residents move into care homes: activities are done for them instead of by them or, indeed, with them. On entering Starrett Lodge, many of the residents would have lost their "roles" as cook, cleaner and so on; for this reason, the BL not only provides many residents with a chance to act in ways that had never been part of their lives (evident in the managerial roles assigned to Marcia and Jessie) but also affords some continuity and identity repair in terms of who they were before they entered the home and their ongoing interests from the past. The residents become "participants" rather than "recipients," with the staff "on tap rather than on top," in the words of Colin McDonell (Finding the Why 8:34, 8:04). From sharing the joy of someone else achieving a goal that they have never been able to achieve, particularly at this stage of their life, to taking on a mentoring "role" when more capable individuals are buddied 
up with those who are more cognitively impaired, the BL is all about building relationships of care.

All the activities take place in a network of relationships with others, as well as with the objects being produced, whether it is biscuits, books or calendars. The care home staff and residents all work together in the kitchen to get the biscuits cooked, which gives the residents an opportunity to be part of a community. All the workers at the home, and the activities officer, are also instrumental in establishing this context of care; that is, they pay attention to and value the skills the residents offer to the BL, recognising and celebrating their input to the collaboration. As Held notes: "[ $t]$ he values of caring are especially exemplified in caring relations, rather than in persons as individuals" (242). Once the money has been raised, often through the activities done by the women in the kitchen, the staff then help to bring the residents' wishes to fruition (Sanchez Interview no. 1). Names are still drawn out of a hat to see whose turn is next.

\section{Rider}

In seeing these practices through the utopian lenses of theatre and performance, the residents at Starrett Lodge have a chance to be seen as full of potential rather than deficient as is the risk with the "diagnostic gaze" (Kuppers 137; Gullette). Although the initiative lies with the spectator in the case of dementia, in particular, in performance there is always a relational element connected to the intersubjective process of encounters over time: herein lies hope for changes to formulaic and regulated ways of interpreting dementia and the people who live with it, and older people more generally. Theatrical narrativisation can help do this.

Unfortunately, practical and organisational changes at Starrett Lodge that were due to the first lockdown resulting from the COVID-19 epidemic in early 2020 affected the operation of the BL. One of the changes was Vicki Sanchez's retirement from paid work at Starrett Lodge. Her role of activities officer was filled by a person who, early in 2020, was unable to return from overseas, so no one was in the role, and the BL was discontinued for a while. Another change was the introduction of a "Household" model to the home, in which the residents spend a typical day at home with all the "spontaneous" activities they want to do facilitated by the care workers. According to Sanchez (Interview no. 2), this model and the BL were sidelined during this time. The attenuation of the $\mathrm{BL}$ points to how important the role of an activities officer is in rallying action regarding the List. It also appears to indicate the importance of the role of specific people in assembling support for the BL, such as Marcia and Jessie. Luckily, the new activities officer is now back in Australia, and the BL is once again operational. 


\section{Conclusion}

As the primary foci of this chapter, the $\mathrm{BL}$ and the CPs underscore the relationship between ageing, illness, care, narrative and performance. Framing these care practices as "narra-theatrical," though they are not interpreted in this way by the participants and the institution, is a theoretical proposition which I have brought to these practices because of my previously expressed desire to explore what can be revealed through the utopian lenses of theatre and performance, and the performance of "roles." In these innovative "care practices," theatrical narrativisation and capacity building through agency emerge as central. Here, care meets possibility (the latter activated through the lenses of theatre and performance), and older people living in care facilities are not marginalised by the "diagnostic gaze" (Kuppers 137) as deficit nor are they sidelined by the "decline narrative" (Gullette 13), because they are not being judged as cognitively wanting, incapable of changing or unable to contribute to their communities in meaningful ways. Through the "narra-theatrical" lens, older people living in care facilities can be seen as productive contributors rather than just recipients of care, "takers" or burdens. Through this lens these residents might step out of their expected "roles" into new ones and in the process constricting narratives which connect them only to their past identities, or, paradoxically, which see them as powerless to live into those past identities if they so choose, might be changed. The role plays and narrative improvisations of the $\mathrm{BL}$ and $\mathrm{CPs}$ open up possibilities for many of the residents at Starrett Lodge to live in new and dynamic ways and to be appreciated by the spectators of these performances of possibility.

\section{Notes}

1. Uniting Care Australia is a nationwide corporation responsible for the Uniting Church's community services arrangements. Aged care in Australia is either run as not-for-profit, for-profit (private) or by the government. Uniting Care is one of the largest not-for-profit organisations in Australia, with more than 550 services across New South Wales and the Australian Capital Territory (Uniting). Though the corporation is connected to a religious body, Uniting Care is committed to "celebrat[ing] diversity of ability, age, ethnicity, faith, sexual orientation, intersex variation or gender identity and welcome[ing] everyone exactly as they are" (www.uniting.org/uniting-careers/ diversity-and-inclusion).

2. The Central Coast Local Government Area has a considerably lower income makeup than Greater Sydney and NSW. In 2019, it was found that median household incomes were "around $70 \%$ of Greater $S y d n e y$, and a much higher proportion of local households were on very low and low incomes" (Community Partnerships).

3. "Theatre" and "performance" are intimately connected terms, with "performance" usually the über-label under which "theatre" sits (Balme). 
4. The film focuses on the personhood and relational approaches encouraged by management and staff at Starrett Lodge (including Colin McDonell, exmanager of Starrett Lodge, and Vicki Sanchez) which help residents to find meaning in their lives. It shows that Starrett Lodge has a unique approach to enabling active participation in life for care residents through methods like paying attention to the environment, for example, bringing more light into the facility; activities such as encouraging residents to write and publish their life stories; intergenerational and interspecies programs, by which babies and animals are brought into the facility; and the innovative Bucket List and other projects.

5. SBS stands for the Special Broadcasting Unit, which has a radio, television and online presence across Australia. It was founded in 1977-1978 to provide ethnic broadcasting to the rapidly changing population demographics resulting from increased migration. "Dancing with Dementia" was an episode of the weekly interview show Insight, which was conducted by Jennie Brockie for nearly two decades up until recently and now has Kumi Taguchi as the anchor. Insight is Australia's leading forum for debate and first-person stories. The "Dancing with Dementia" episode included a panel of people and their families, as well as audience members, living with dementia and people working in the field. The Bucket List and the Calendar Projects are given time along with an interview with Colin McDonell, who was the Starrett Lodge manager at the time. Around 26 minutes into the show, the residents are filmed in the kitchen wrapping biscuits in cellophane and adding blue ribbons to them.

6. Multiple versions of (feminist) care ethics (Held 169) have emerged over the past 30 years. In general, care ethicists argue that universal moralities, built on the image of the autonomous, rational, independent, "agentic" individual, overlook the reality of human interdependence and that, for so many stages of human life, we are dependent on others to survive and flourish. The ethics of care "addresses rather than neglects moral issues arising in relations among the unequal and dependent" (Held 13), which is the case in relationships between so called "cognitively intact" people and PLWD.

7. Thompson's hope that this aesthetics "could be orientated as much to institutional care practices as it might be to community-based theatre" (440) was one of the inspirations for this chapter.

8. Social citizenship as defined by Bartlett and O'Connor (Broadening the Dementia Debate) is a view of citizenship which sees civic agency in people as contributing to the socio-cultural mechanics of the contexts in which they live.

9. In criticizing the "diagnostic gaze," I am fully cognisant that diagnoses often have helpful and therapeutic purposes and outcomes. PLWD, many older people and their care partners require access to expert medical care and support services whose provision rests, to a certain extent, on diagnostic definitions and categories. Without definitive medical assessment and certification, persons who require support, as well as their care partners, would not have their needs met by institutionalised services.

10. I prefer the term "care partner" to that of carer or even caregiver, to acknowledge the relational nature of interactions between the people involved in care practices - whether these interactions occur between the older people or PLWD themselves, or the care workers or family members or friends of the care home residents. But for the sake of descriptive precision, it is sometimes important for me to use phrases such as carer or care attendant. 
11. I use the terms "narrative" and "story" interchangeably, despite the fact that certain literary studies scholars define these terms discretely, with "story" as the events that happen and "narrative" as the showing or telling of those events involving sequence (movement from beginning to finish), space (detours from the sequence) and time (Cobley 5-17). For philosopher Paul Ricoeur (Time and Narrative), "narrative" is time; it is about expectation and memory and not just paying attention to events on a timeline. However, I am guided here by Arthur Frank's contention that the words "narrative" and "story" overlap so frequently that sustaining divisions between them in consistent usage is impossible. Frank also refuses a formal definition of stories, contending that stories, in their very ontology, constantly evade classification.

12. In the UK, this has not always been the case. See, for example, the original WI calendar girls.

13. This project was once again inspired by a film, as was The Bucket List. This time, it was the 2003 film Calendar Girls.

\section{Works Cited}

Balme, Christopher. The Cambridge Introduction to Theatre Studies. Cambridge UP, 2008.

Bartlett, Ruth, and Deborah O'Connor. Broadening the Dementia Debate: Towards Social Citizenship. Policy Press, 2010.

Bitenc, Rebecca. Reconsidering Dementia Narratives: Empathy, Identity and Care. Routledge, 2020.

Black, Steven P. "The Ethics and Aesthetics of Care." Annual Review of Anthropology, vol. 47, no. 1, 2018, pp. 79-95.

Bleeker, Maikke. Visuality in the Theatre: The Locus of Looking. Palgrave Macmillan, 2011.

Buch, Elena D. "Anthropology of Aging and Care." Annual Review of Anthropology, vol. 44, no. 1, 2015, pp. 277-93.

Burke, Lucy. "The Locus of Our Dis-Ease." Popularizing Dementia: Public Expressions and Representations of Forgetfulness. Edited by Aagje Swinnen and Mark Schweda, Aging Studies, vol. VI. Transcript, 2015, pp. 23-41.

Butler, Robert N. "The Life Review: An Interpretation of Reminiscence in the Aged." Psychiatry, vol. 26, no. 1, 1963, pp. 65-70.

Cobley, Paul. Narrative. Routledge, 2001.

Community Partnerships. Submission to Federal Government - Raise the Rate for Newstart and Youth Allowance. Central Coast Council Wyong Office, 2019.

Das, Anita. "A Silver Tsunami Invades the Health of Nations.” Forbes. 11 Aug. 2015, www.forbes.com/sites/reenitadas/2015/08/11/a-silver-tsunami-invadesthe-health-of-nations/?sh=4356603efd67.

Dolan, Jill. Utopia in Performance: Finding Hope at the Theater. U of Michigan P, 2005.

Frank, Arthur W. Letting Stories Breathe: A Socio-Narratology. U of Chicago P, 2010.

Gibson, Janet. Dementia, Narrative and Performance: Staging Reality, Reimagining Identities. Palgrave Macmillan, 2020.

Gullette, Margaret Morganroth. Aged by Culture. U of Chicago P, 2004. 
Held, Virginia. The Ethics of Care: Personal, Political, and Global. Oxford UP, 2006.

Kelleher, Joe. Theatre and Politics. Palgrave Macmillan, 2009.

Kittay, Eva Feder. "The Completion of Care - With Implications for a Duty to Receive Care Graciously." Care Professions and Globalization. Edited by Ana Marta González and Craig Iffland. Springer, 2014, pp. 33-42.

Kuppers, Petra. "Towards the Unknown Body - Silence, Stillness, Space in Mental Health Settings.” Theatre Topics, vol. 10, no. 2, 2000, pp. 129-43.

Leibing, Annette. "Entangled matters - Alzheimer's, Interiority, and the 'Unflattening' of the World." Culture, Medicine and Psychiatry, vol. 32, no. 2, 2008, pp. 177-93.

Lloyd, Jayne. "Taking Care of the Laundry in Care Homes." Performing Care: New Perspectives on Socially Engaged Performance. Edited by Amanda Stuart Fisher and James Thompson. Manchester UP, 2020, pp. 204-14.

Mangan, Michael. Staging Ageing: Theatre, Performance and the Narrative of Decline. Intellect, 2013.

Mitchell, David T., and Sharon L. Snyder. The Biopolitics of Disability: Neoliberalism, Ablenationalism, and Peripheral Embodiment. U of Michigan P, 2015.

Noddings, Nel. Caring: A Relational Approach to Ethics and Moral Education. U of California P, 2013.

Pavis, Patrice. Analyzing Performance: Theater, Dance, and Film. Translated by David Williams. U of Michigan P, 2003.

Quick, Andrew, and Richard Rushton. "On Theatricality." Performance Research, vol. 24, no. 4, 2019, pp. 1-4, https://doi.org/10.1080/13528165.20 19.1655350.

Ricoeur, Paul. Time and Narrative. Translated by Kathleen Blamey and David Pellauer, vol. 3. U of Chicago P, 1988.

Sanchez, Vicki. Personal Interview no. 1. Friday 17 Aug. 2018.

—. Personal interview no. 2. Friday 29 May 2020.

- Personal interview no. 3. Tuesday 9 Nov. 2020.

- Personal interview no. 4. Monday 29 Mar. 2021.

Schechner, Richard. Between Theatre and Anthropology. U of Pennsylvania $\mathrm{P}, 1985$.

- Performance Studies: An Introduction. 4th ed. Routledge, 2020.

States, Bert O. "Performance as Metaphor." Performance: Critical Concepts in Literary and Cultural Studies. Edited by Philip Auslander, vol. 1. Routledge, 2003, pp. 108-37.

Stuart Fisher, Amanda. "Introduction: Caring Performance, Performing Care." Performing Care: New Perspectives on Socially Engaged Performance. Edited by Amanda Stuart Fisher and James Thompson. Manchester UP, 2020, pp. 1-17.

Thompson, James. "Towards an Aesthetics of Care." Research in Drama Education: The Journal of Applied Theatre and Performance, vol. 20, no. 4, 2015, pp. 430-41.

Uniting. About Us. www.uniting.org/about-us\#: :text=We're\%20proud\%20 to $\% 20$ be, disability $\% 2 \mathrm{C} \% 20$ chaplaincy $\% 20$ and $\% 20$ community $\% 20$ services. Accessed 12 Oct. 2020. 


\section{Janet Gibson}

van de Kamp, Jeannet. "The Completion of Care as Taking Up of Another's Actions as Care.” Interview with Eva Feder Kittay, 28 Jan. 2018, https:/ethic sofcare.org/completion-care-taking-anothers-actions-care/.

\section{Filmography}

The Bucket List. Directed by Rob Reiner. Warner Brothers, 2007.

Dancing with Dementia. Season 2015, episode 11, SBS Insight, 28 Apr. 2015, 7 Jun. 2020, www.sbs.com.au/ondemand/video/428900419962.

Finding the Why; Enabling Active Participation in Life in an Aged Care Facility. Directed by Corinne Maunder. Co-produced by Corrine Maunder and Cathy Greenblatt. Fire Films Australia, 2014, www.youtube.com/ watch? $\mathrm{v}=\mathrm{hZN} 1 \mathrm{CyEiFNM}$.

It Takes a Community - A Relationship Focused Approach to Celebrating and Supporting Old Age. Directed by Corinne Maunder. Co-produced by Corrine Maunder and Cathy Greenblatt. Fire Films Australia, 12 Nov. 2017, www. youtube.com/watch?v=IUJWFWXz-wY. 